\title{
Thermodynamic parameters and phase transformations of zinc selenide crystals: quantum-chemical calculations
}

\author{
Dmytro FREIK ${ }^{1}$, Taras PARASHCHUK ${ }^{1 *}$, Nataliya FREIK ${ }^{1}$, Anatoliy GREBENYUK ${ }^{2}$ \\ ${ }^{1}$ Precarpathian National Vasyl Stefanyk University, \\ Shevchenka St. 57, 76018 Ivano-Frankivsk, Ukraine \\ ${ }^{2}$ Chuiko Institute of Surface Chemistry, National Academy of Sciences of Ukraine, \\ General Naumov St. 17, 03164 Kyiv, Ukraine \\ * Corresponding author. Tel.: +380-34-2759214; fax:+380-34-2759214; e-mail: taras-parashchuk@i.ua
}

Received August 9, 2012; accepted December 26, 2012; available on-line July 5, 2013

Molecular models for polymorphic modifications of zinc selenide have been designed. Based on the results of quantum-chemical calculations of the structure and properties of clusters, the enthalpy of formation and Gibbs energy of the sphalerite- and wurtzite-type modifications have been computed, and the temperature for the phase transformation "sphalerite-wurtzite" estimated.

Zinc selenide / Sphalerite / Wurtzite / Cluster models / Quantum chemistry

\section{Термодинамічні параметри та фазові перетворення у кристалах цинк селеніду: квантово-хімічний розрахунок}

\author{
Дмитро ФРЕЇК ${ }^{1}$, Тарас ПАРАЩУК $^{1 *}$, Наталія ФРЕЇК ${ }^{1}$, Анатолій ГРЕБЕНЮК $^{2}$ \\ ${ }^{1}$ Прикарпатський національний університет імені Василя Стефаника, \\ вул. Шевченка 57, 76018 Івано-Франківськ, Україна \\ ${ }^{2}$ Інститут хімї̈ поверхні ім О.О. Чуйка НАН Украӥни, \\ вул. Генерала Наумова 17, 03164 Київ, Украӥна \\ * Контактна особа. Тел.: +380-34-2759214; факс:+380-34-2759214; e-mail: taras-parashchuk@i.ua
}

Побудовано молекулярні моделі поліморфних модифікацій кристалів цинк селеніду. На підставі результатів квантово-хімічних розрахунків структури та властивостей кластерів визначено ентальпії утворення та енергії Гіббса сфалеритної та вюрцитної модифікацій напівпровідника та їхні температурні залежності, а також зроблено оцінку температури фазового переходу “сфалеритвюрцит".

Цинк селенід / Сфалерит / Вюрцит / Кластерні моделі / Квантова хімія

Вступ

Цинк селенід - перспективний матеріал для створення світлодіодів, фоторезисторів, джерел спонтанного і когерентного випромінювання [1]. Його ширина забороненої зони становить $E_{g}=2,7$ еВ при $T=300$ К, що відповідає синьоблакитній області спектра [2]. Даний напівпровідник кристалізується таким чином, що кожен атом $\mathrm{Zn}(\mathrm{Se})$ розміщений у центрі правильного тетраедра, в чотирьох вершинах якого знаходяться атоми іншого елемента $\operatorname{Se}(\mathrm{Zn}) .3$ таких тетраедрів можливе утворення двох типів структур: сфалерит (кубічна) та вюрцит (гексагональна).

Низькотемпературна модифікації 3C $\mathrm{ZnSe}$ (сфалерит) відноситься до кубічної сингонії, просторова група $F-43 m$ [3]. У структурі сфалериту атоми цинку розміщені у вузлах гранецентрованої кубічної гратки. Атоми селену 
утворюють подібну гратку i розташовуються таким чином, що кожен атом селену оточений чотирма атомами цинку. Координаційне число атомів цинку також рівне чотирьом.

Високотемпературна модифікація $2 \mathrm{H} \quad \mathrm{ZnSe}$ (вюрцит) відноситься до гексагональної сингонії, просторова група $P 6_{3} m c$. Атоми селену у вюрциті займають положення, які близькі до гексагональної щільної упаковки. Координаційне число атомів цинку і селену зберігається рівним чотирьом [3]. Стала гратки для кубічної структури $\mathrm{ZnSe} a=5,667 \AA$, а для гексагональної $a=3,996 \AA, c=6,550 \AA$ [4]. Сполуки із структурою типу сфалериту більш стабільні, ніж із структурою типу вюрциту, оскільки енергія його кристалічної гратки є дещо меншою.

У літературі представлені досить суперечливі дані про поліморфізм цинк селеніду, а також відсутні достовірні термодинамічні параметри. Так, зокрема, температура фазового переходу кубічної модифікації ZnSe у гексагональну визначена у роботі [5] становить $1698 \mathrm{~K}$, у роботі [6] - 1713 К, а у роботі [7] - 1684 К. Авторами [3] представлена температура поліморфного переходу $T=1420 \mathrm{~K}$, яка суттєво відрізняється від попередніх значень. На стійкість сфалериту і вюрциту впливають різні фактори: зміна температури, зовнішнього тиску, концентрації домішок [8]. Що стосується термодинамічних параметрів, то тільки $\epsilon$ дані про ентальпію утворення сфалеритної модифікації $\mathrm{ZnSe}$ $\Delta H_{\kappa p}=177$ кДж/моль при нормальних умовах [4].

У даній роботі $a b$ initio методами квантової хімії визначено термодинамічні характеристики сфалеритної і вюрцитної модифікацій кристалів цинк селеніду, а також температуру їхнього фазового переходу.

\section{Структурні моделі кластерів}

Для розрахунку термодинамічних параметрів використано кластерний підхід [9]. Розрахунок проводили за допомогою пакету програм FireFly в рамках обмеженого методу Хартрі-Фока, 3 використанням валентного базисного набору SBKJC [10], який включає ефективний остовний потенціал [11]. Візуалізація просторових структур здійснювалася з використанням Chemcraft.

Для розрахунку сфалериту були використані дві кластерні моделі цинк селеніду: кластери А і В. Модель А включає атом цинку, оточений двома дводендатними лігандами, і має загальну формулу $\mathrm{ZnC}_{2} \mathrm{H}_{2} \mathrm{Se}_{4}$ (Рис. 1,a). Кластер B, загальна формула якого $\mathrm{Zn}_{4} \mathrm{C}_{6} \mathrm{H}_{6} \mathrm{Se}_{13}$, містить атом цинку, оточений чотирма атомами селену, що відповідає реальному кристалу; всі ці атоми чотирикоординовані. Для насичення граничних зв'язків використовували шість лігандів складу $\mathrm{HCSe}_{2}$ (Рис. 1,б).

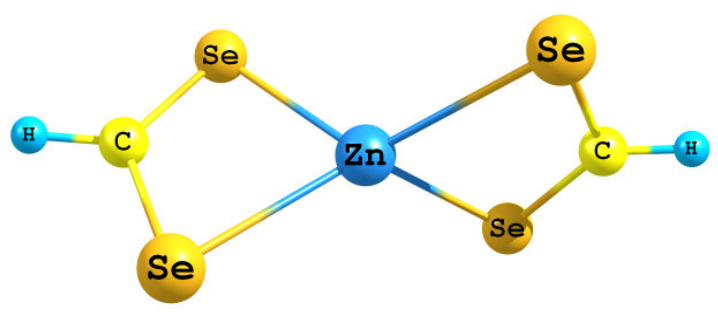

(a)

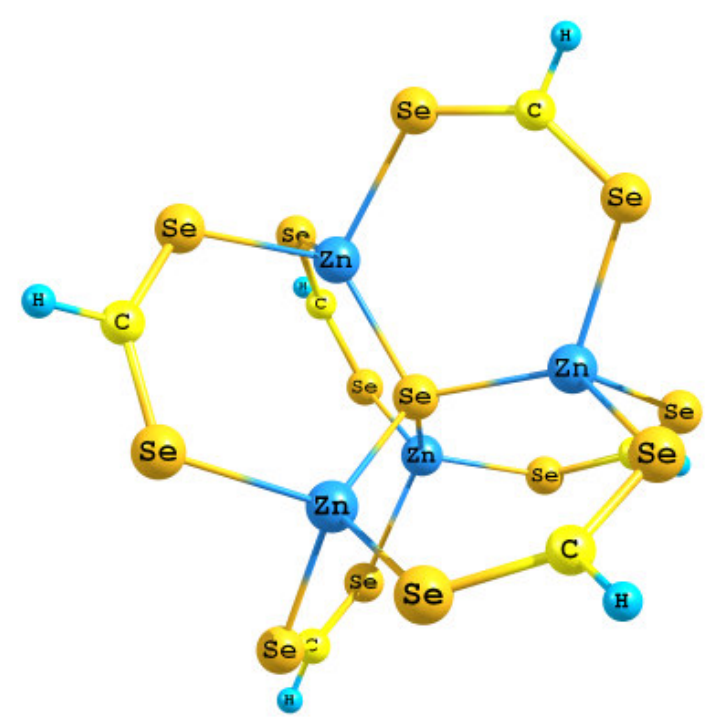

(б)

Рис. 1 Візуальне зображення кластерів A $\left(\mathrm{ZnC}_{2} \mathrm{H}_{2} \mathrm{Se}_{4}\right)$ (a) i B $\left(\mathrm{Zn}_{4} \mathrm{C}_{6} \mathrm{H}_{6} \mathrm{Se}_{13}\right)$ (б), відповідно.

Структура вюрциту досліджена за допомогою трьох моделей: C, D, Е. Модель C (загальна формула $\mathrm{Zn}_{15} \mathrm{Se}_{15}$, Рис. 2,a) $є$ базовою для розрахунку просторової та електронної будови, а також термохімічних величин. Дана модель складається 330 атомів i містить дві чотирикоординовані пари, вісім трикоординованих пар та п'ять двокоординованих пар атомів. Кластер D (3 загальною формулою $\mathrm{Zn}_{11} \mathrm{Se}_{11}$, Рис. 2,б) складається 322 атомів. Він містить одну чотирикоординовану, шість трикоординованих i чотири двокоординовані пари атомів. Кластер Е вюрцитної модифікації (з загальною формулою $\mathrm{Zn}_{10} \mathrm{Se}_{10}$, Рис. 2,в) складається 320 атомів. Він містить одну чотирикоординовану, чотири трикоординованих і п’ять двокоординованих пар атомів.

\section{Розрахунок та його результати}

При обчисленні ентальпії $\Delta H$ утворення сфалеритної фази використовували два 


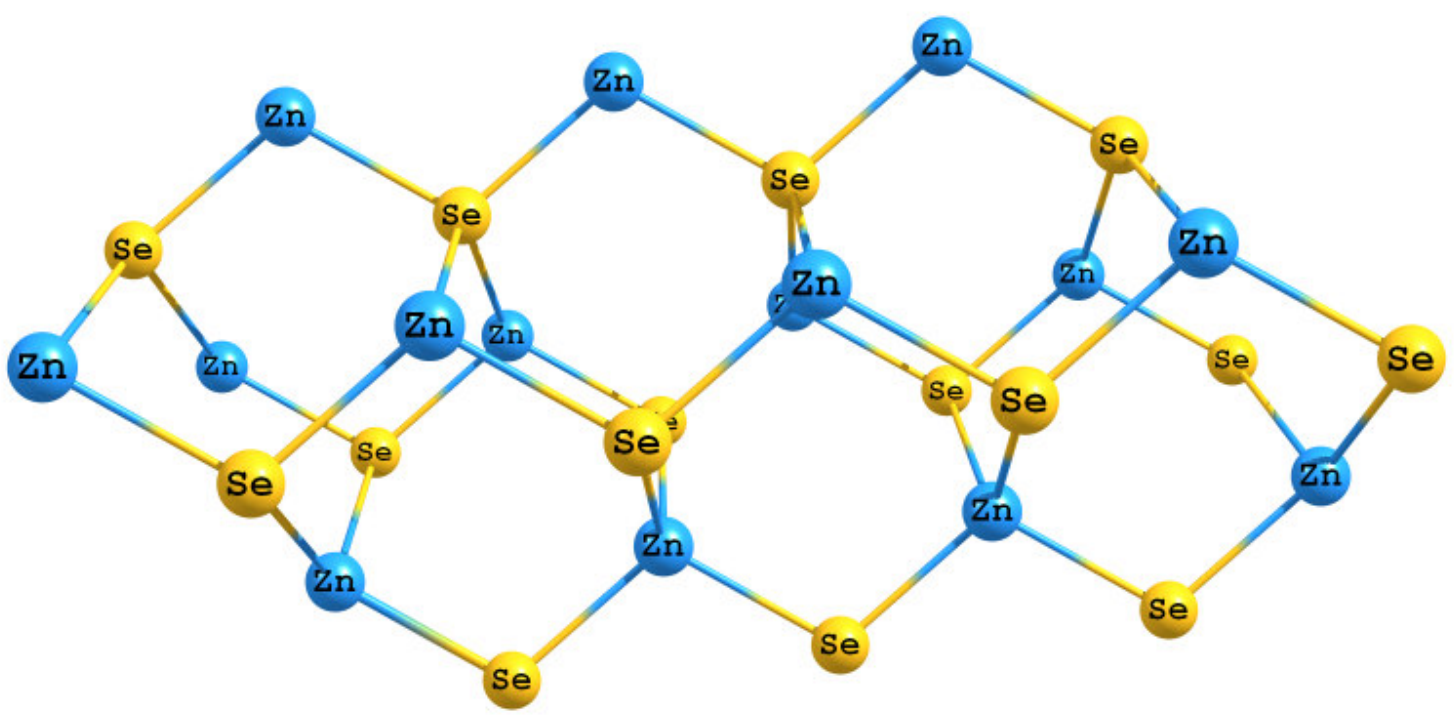

(a)

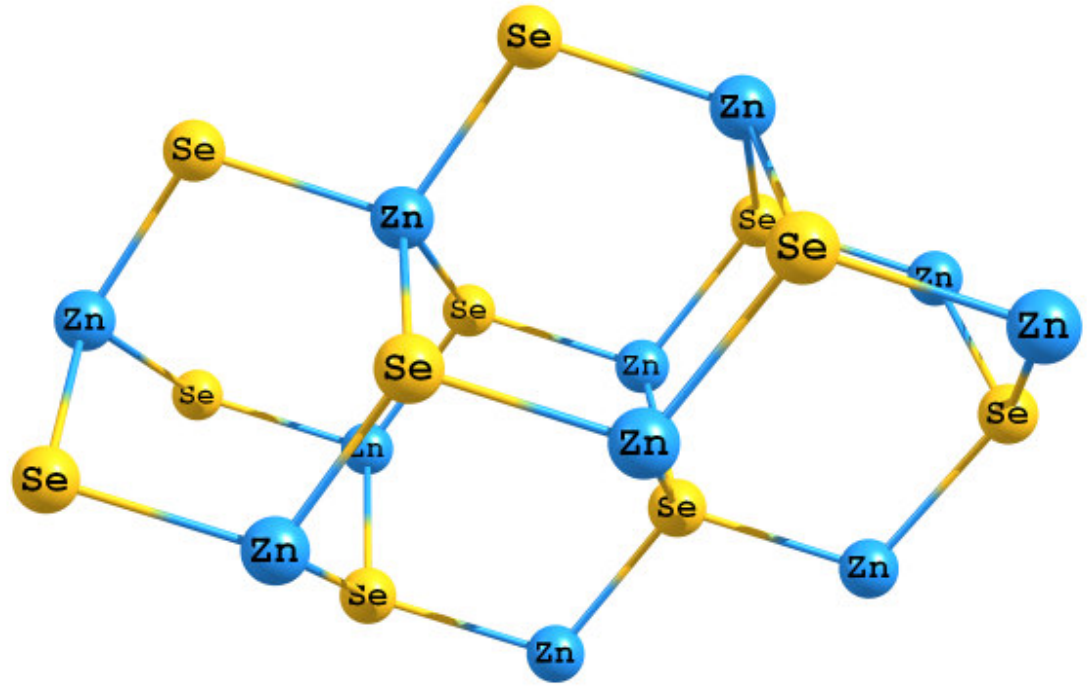

(б)

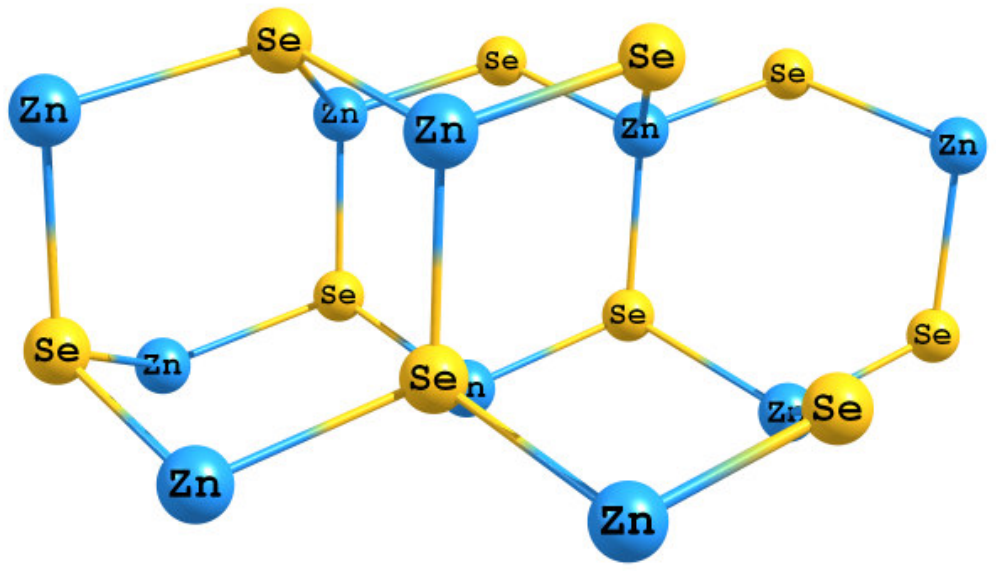

(B)

Рис. 2 Візуальне зображення кластерів C $\mathrm{Zn}_{15} \mathrm{Se}_{15}$ (a), D Zn $\mathrm{Zn}_{11} \mathrm{~S}_{11}$ (б), $\mathrm{E} \mathrm{Zn}_{10} \mathrm{Se}_{10}$ (в), відповідно. 
кластери. Спочатку розраховували ентальпію кластера А, згідно з [12]:

$\Delta H=T-\sum E_{\text {eл }}+\sum \Delta H_{\text {am }}$

де $T$ - загальна енергія системи, $E_{\text {ел }}$ - електронна енергія атомів, що складають систему (в атомарному стані), $\Delta H_{a m}-$ енергія атомізації атомів. Загальну енергію системи отримано 3 результатів розрахунку, а всі інші величини - із довідникових матеріалів [14]. Аналогічним чином була розрахована ентальпія утворення кластера В. Після цього від ентальпії утворення кластера В віднімали потрійну величину ентальпії утворення кластера А, тобто, від величини ентальпії кластера, що складається із фрагменту кристала сфалериту та трьох лігандів, віднімали ентальпію трьох лігандів. Отримане значення цієї величини можна віднести до ентальпії $\Delta H_{1}(T)$ реального кристала сфалериту [13].

Для розрахунку ентальпії утворення вюрциту $\Delta \mathrm{H}_{2}(T)$ спочатку розраховували ентальпії утворення трьох кластерів $\Delta H_{C}, \Delta H_{D}, \Delta H_{E}$ за методикою описаною вище, а потім складали систему рівнянь:

$$
\left\{\begin{array}{c}
2 \Delta H_{4}^{*}+8 \Delta H_{3}^{*}+5 \Delta H_{2}^{*}=\Delta H_{C} \\
\Delta H_{4}^{*}+6 \Delta H_{3}^{*}+4 \Delta H_{2}^{*}=\Delta H_{D} \\
\Delta H_{4}^{*}+4 \Delta H_{3}^{*}+5 \Delta H_{2}^{*}=\Delta H_{E}
\end{array}\right.
$$

де коефіцієнти біля $\Delta H_{i}^{*}$ відповідають кількості пар зв'язків у відповідних кластерах із координаційним числом, що дорівнює індексу $i=2,3,4$ біля $\Delta H_{i}^{*}, \Delta H_{C}, \Delta H_{D}$ та $\Delta H_{E}-$ ентальпї кластерів C, D, Е, відповідно, $\Delta H_{4}^{*}$ - величина ентальпії утворення кристала для даної температури.

Систему рівнянь (2) розв'язували аналітично за допомогою оберненої матриці 3 використанням формул Крамера. У результаті отримано таке співвідношення для визначення ентальпії утворення вюрцитної модифікації кристалів цинк селеніду:

$\Delta H_{4}^{*}=\frac{7 \Delta H_{C}-10 \Delta H_{D}+\Delta H_{E}}{5}$

Температурні залежності ентальпії утворення кристалів цинк селеніду для сфалеритної та вюрцитної модифікацій представляють такою системою рівнянь (Рис. 3):

$$
\begin{aligned}
& \Delta H_{1}(T)=0,1533 \cdot T+104,11 \\
& \Delta H_{2}(T)=-0,4213 \cdot T+2011,5
\end{aligned}
$$

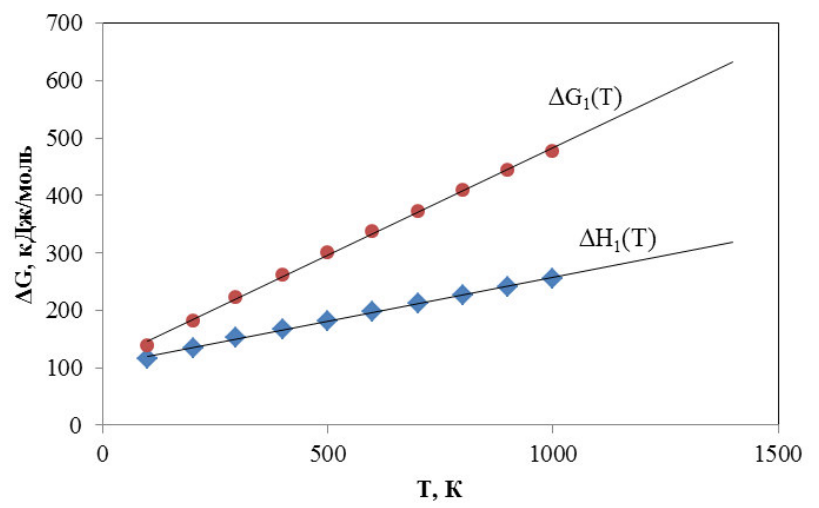

(a)

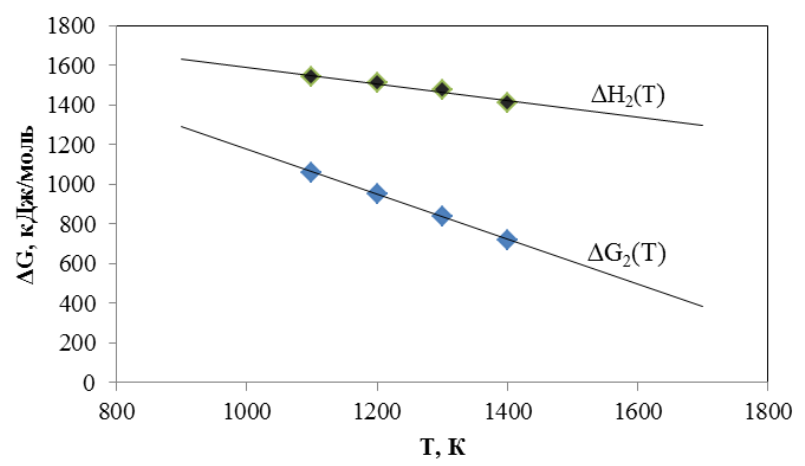

(б)

Рис. 3 Температурні залежності ентальпій утворення $\Delta H_{1,2}(T)$ та енергій Гіббса $\Delta G_{1,2}(T)$ для сфалеритної (а) та вюрцитної (б) модифікацій кристалів ZnSe. 
На основі розрахованих коливальних спектрів визначено енергії Гіббса сфалериту $\Delta G_{1}(T)$ i вюрциту $\Delta G_{2}(T)$ при різних температурах. Для врахування граничних умов використовували допоміжні кластери: кластер А - для сфалериту, кластери D, E - для вюрциту.

У випадку із сфалеритом від величини $\Delta G$ утворення кластера В віднімали потрійну величину $\Delta G$ утворення кластера А. Тобто, від $\Delta G$ кластера, що складається 3 фрагменту кристала сфалериту та трьох лігандів, віднімали $\Delta G$ трьох лігандів. Отримане значення енергії Гіббса $\Delta G_{1}(T)$ можна віднести до кристала сфалериту.

Для розрахунку енергії Гіббса $\Delta G_{2}(T)$ кристала вюрциту спочатку розраховували енергію Гіббса кластерів C, D, E за методикою описаною вище, а потім складали систему рівнянь:

$$
\left\{\begin{array}{l}
2 \Delta G_{4}^{*}+8 \Delta G_{3}^{*}+5 \Delta G_{2}^{*}=\Delta G_{C} \\
\Delta G_{4}^{*}+6 \Delta G_{3}^{*}+4 \Delta G_{2}^{*}=\Delta G_{D} \\
\Delta G_{4}^{*}+4 \Delta G_{3}^{*}+5 \Delta G_{2}^{*}=\Delta G_{E}
\end{array}\right.
$$

де коефіцієнти перед $\Delta G_{i}^{*}$ відповідають кількості пар зв'язків із координаційним числом, що дорівнює індексу $i=2,3,4$ біля $\Delta G_{i}^{*}, \Delta G_{C}, \Delta G_{D}$ i $\Delta G_{E}$ - енергії Гіббса кластерів C, D, Е, відповідно. Тоді $\Delta G_{4}^{*}$ - шукана величина енергії Гіббса для кристала при заданій температурі.

Систему рівнянь розв'язували аналогічно до системи (2). У результаті було отримане таке співвідношення для енергії Гіббса вюрцитної модифікації $\mathrm{ZnSe}$ :

$\Delta G_{4}^{*}=\frac{7 \Delta G_{C}-10 \Delta G_{D}+\Delta G_{E}}{5}$
Температурні залежності енергії Гіббса для сфалериту i вюрциту кристалів цинк селеніду $\Delta G_{1}(T), \Delta G_{2}(T)$, представлені на Рис. 4, а їхні аналітичні вирази мають вигляд:

$\Delta G_{1}(T)=0,4135 \cdot T+87,506$

$\Delta G_{2}(T)=-1,2464 \cdot T+2455,8$

Із хімічної термодинаміки відомо, що при переході речовини із однієї фази в іншу, в тому числі при поліморфних фазових переходах, реакція буде відбуватися до тих пір, поки ентропії однієї і другої фаз стануть однаковими. Тобто, взявши до уваги співвідношення $S=-\frac{\Delta G}{\Delta T}$, стає очевидним, що рівність величини $\Delta G$ для сфалериту i вюрциту при тій же температурі визначає температуру фазового переходу $T_{\kappa}$ між даними модифікаціями. У нашому випадку точка перетину залежностей $\Delta G_{1}(T)$ і $\Delta G_{2}(T)$ за умови виконання рівності $\Delta G_{1}(T)=\Delta G_{2}(T)$, буде відповідати температурі фазового переходу від сфалериту до вюрциту, яка для цинк селеніду становить $T_{\kappa}=1427 \mathrm{~K}$.

\section{Висновки}

1. Запропоновано кластерні моделі сфалеритної та вюрцитної модифікацій кристалів цинк селеніду. Представлено методику врахування граничних умов для даних моделей.

2. Визначено термодинамічні параметри кристалу: ентальпії утворення кожної 3 поліморфних модифікацій, а також їхні температурні залежності. Підтверджено гіпотезу про те, що

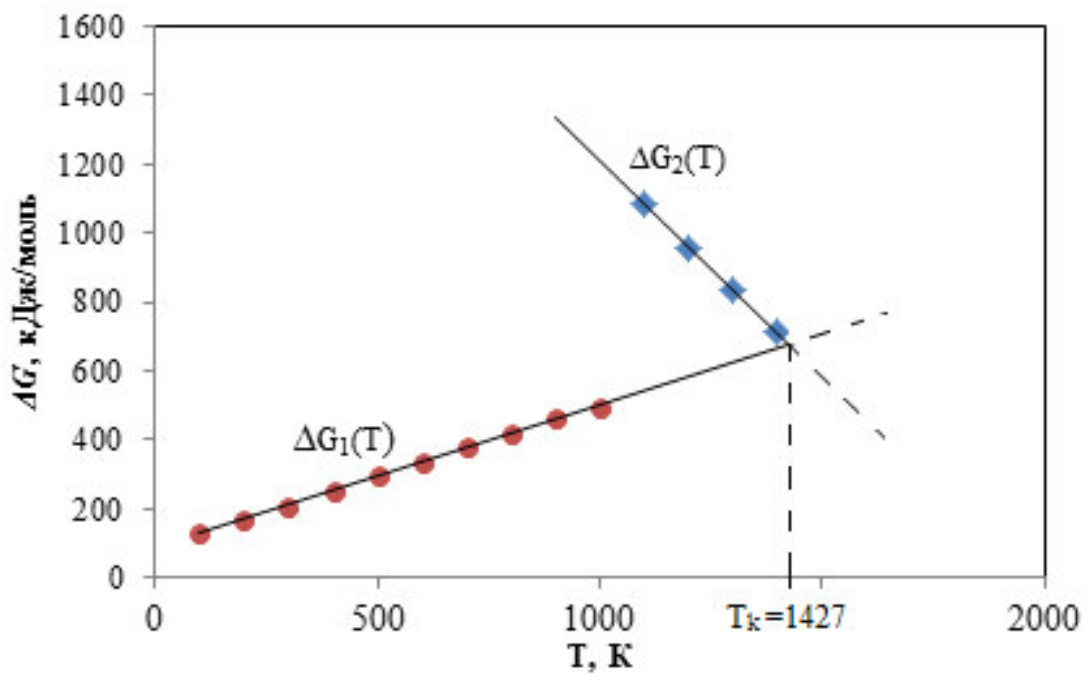

Рис. 4 Температурна залежність енергії Гіббса для сфалеритної $\Delta G_{1}(T)$ і вюрцитної $\Delta G_{2}(T)$ фаз ZnSe. 
сфалеритна модифікація $\mathrm{ZnSe} є$ більш стійкою по відношенню до вюрцитної.

3. Побудовано температурні залежності енергій Гіббса кристалів цинк селеніду для даних поліморфних модифікацій. Розраховано температуру фазового переходу сфалерит-вюрцит, величина якої становить $T=1427$ К.

Робота виконана згідно наукових проектів Державного агентства з питань науки, інновацій та інформацї Украӥни (державний реєстраційний номер 0110U007675) та МОН України (державний реєстрачійний номер 0107U006768).

\section{Літературні посилання}

[1] Д.М. Фреїк, Г.Я. Бабущак, Ю.І. Семенишин, Фіз. хім. тв. тіла 7 (2006) 701-707.

[2] Д.М. Фреїк, Г.Я. Бабущак, П.В. Жуковські, В.І. Левченко, Фіз. хім. тв. тіла 9 (2008) 274-279.

[3] С.А. Медведева, Физика и химия соединений $A^{I I} B^{V I}$, Мир, Москва, 1970, 624 с.
[4] Н.С. Зефиров, Химическая энциклопедия. Том 5, Большая Российская энциклопедия, Москва, 1998, 783 с.

[5] М.П. Кулаков, В.Д. Кулаковський, И.Б. Савченко, А.В. Фадеев, Физ. тверд. тела 18 (1976) 909-911.

[6] I. Kikuma, M. Furukoshi, J. Cryst. Growth 71 (1985) 136-140.

[7] H. Okada, T. Kawanaka, S. Ohmoto, J. Cryst. Growth 165 (1996) 31-36.

[8] Н.Х. Абрикосов, Полупроводниковые соединения, их получение и свойства, Наука, Москва, 1970, 205 с.

[9] В.А. Губанов, Е.З. Курмаев, А.Л. Ивановский, Квантовая химия твёрдого тела, Наука, Москва, 1984, 304 с.

[10] J. Breidung, W. Thiel, A. Komornicki, Phys. Lett. 153 (1988) 76-81.

[11] http://classic.chem.msu.su/gran/gamess/index.html.

[12] А.Г. Гребенюк, Наукові записки НаУКМА. Хімічні науки 18 (2000) 25-33.

[13] Г.М. Жидомиров, И.Д. Михейкин, Строение молекул и химическая свіязь (Итоги науки и техники ВИНИТИ АН СССР) 9 (1984) 3-161.

[14] В.П Глушко, Термодинамические свойства индивидуальных веществ. Справочное издание в 4-х т., Наука, Москва, 1978-1981. 